\title{
MULTIVARIABLE FUZZY CASCADE COMPENSATION
}

\author{
R. Ferreiro García, F. J. Pérez Castelo, J. Vidal Paz \\ Dep. Industrial Engineering. University of A Coruna \\ E.S Marina Civil, Paseo de Ronda 51. 15011- A Coruna. Spain \\ fax: 3481167101 \\ e-mail: ferreiro@udc.es \\ ${ }^{\dagger}$ ECC2001 Conference \\ e-mail: ecc2001efe.up.pt \\ http://www.fe.up.pt/ecc2001/
}

Keywords: Non-linear cascade, multivariable disturbances, multivariable cascade compensation, fuzzy cascade compensation.

\begin{abstract}
This work deals with some practical aspects of fuzzy PID controllers regarding multivariable non-linear cascade compensation. This contribution concerns to the task of compensation for multivariable disturbances on the manipulated variable. The strategy consists in establishing a fuzzy rule base for all disturbance variables which afect the manipulated variable and compensate the control variable by cascade action by means of the proposed fuzzy rule base properly adjusted.
\end{abstract}

\section{Introduction}

Conventional cascade control deals with the task of correct the manipulated variable disturbances affecting the servoactuataron or some properties inherent to manipulated variable. Most common industrial processes are disturbed by more than a variable. For instance, in heat exchangers, manipulated variable can be disturbed by input pressure and temperature of the heating fluid.

If the manipulated variable affects one variable and then this variable affects a second controlled variable, the structure leads to series cascade control [4,6]. The effect of a cascade controller is the one of a inner feedback loop. Feedback inner loop data, can be measured directly or calculated by means of a proper math-model. Modelling erros can introduce a source of disturbances. When modelling errors are relevant, then experimental data vía parameter identification is strongly recomended. In any case, uncertainties inherent to the variables and parameters related to the manipulated variable generate powerfull reasons to develop fuzzy cascade controllers.

Figures 1 and 2 show the basic structure for cascade control applied on two industrial typical processes. Then the master controller output supplies the set point, that is the desired torque. In Figure 1 cascade is applied to achieve the torque as function of rudder angle and ship speed. In Figure 2 cascade is applied to achieve the heat flow of heating fluid as funciton of mass flow, input and output temperatures of heating fluid. The master controller output supplies the set point, that is theheat flow of heating fluid.

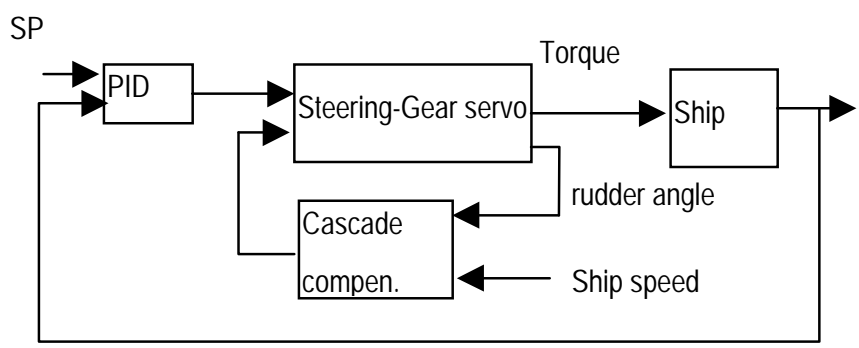

Figure 1: Cascade structure for a ship course control.

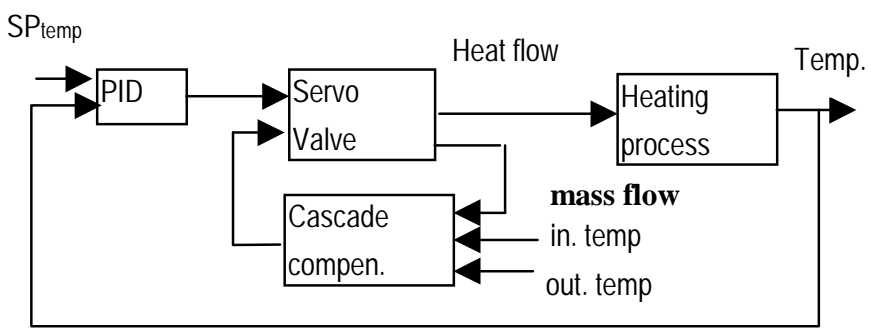

Figure 2: Cascade structure for a heat exchanger.

\section{Application of fuzzy cascade compensation to heading control}

\subsection{Ship model}

Using Newton's equations to the describe ship motion, it will be illustrated how the speed and influence the ship heading motion. In order to simplify yet more the ship motion equations for analysis purposes only, the transfer function may be expressed by a Nomoto model [1] as:

$$
\frac{\Psi}{\delta}=\frac{b}{s(s+a)}
$$

where coefficients $a$ and $b$ were achieved from experimental sea trials [1] and are defined as: 


$$
a=a_{0}\left(\frac{u}{l}\right) ; \quad b=0.5\left(\frac{u}{l}\right)^{2} \frac{A . l}{D}
$$

where $A$ is the rudder area or rudder control surface (in square meters), $D$ is the ship displacement (in cubic meters), $u$ is the ship velocity and $l$ is the ship length.

In order to define the ship transfer function for a steering system whose output is the steering servo torque or turning moment exerted on the ship hull, a math-model relating the rudder angle and rudder torque is defined from information of [2,5] as function of ship speed by:

$$
N=12 \cdot A \cdot l \cdot u^{2} \delta
$$

According Newton's equations of motion applied on same ships, a similar transfer function model with same coefficients but different meaning and values may be achieved as:

$$
\frac{\Psi}{N}=\frac{b^{\prime}}{s(s+a)}
$$

where $b^{\prime}$ is achieved by introducing (3) into (1) to give (4). The result of mentioned manipulation yields the coefficient $b$ ' as:

$$
b^{\prime}=\frac{1}{24 \cdot l^{2} D}
$$

which does not depend on longitudinal ship velocity.

Nevertheless, the problem solving strategy is very much different at variable low speed that is when more manoeuvring capacity is needed. It is due to the interaction between rudder effect, and hull with propeller action. The interaction model is a non-linear function of ship speed, propeller action and rudder angle. So that, the results of mentioned interaction affect the modelling errors inherent to the identification task. As consequence, the use of ship longitudinal speed into an adaptive algorithm at low variable speeds, is not effective because of the uncertainties and an approach for comparative analysis will be based in the Newtonian non-linear dynamic model associated to propulsion and disturbances model.

\subsection{Cascade compensation structure}

Simplified achieved math-models of the ship and its respective steering machines, described by expressions (1-5) associated to a closed-loop controller will be applied on dynamic simulation.

A general scheme to describe the simulation model is shown in Figures 3 and 4.

In Figure 3 it is shown the conventional rudder angle feedback servo commanded by a PID controller to act on the model of the ship previously described by expression (1). Cascade compensation is based on the rudder angle only.

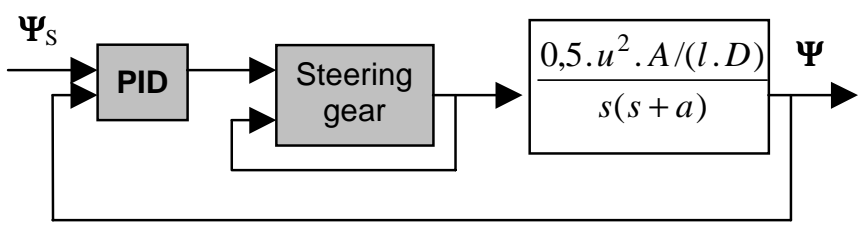

Figure 3: Simulation model for rudder conventional cascade.

In Figure 4 it is shown the rudder angle feedback servo commanded by a PID controller to act on the model of the ship previously described by expression (4). Cascade compensation is based on rudder angle and ship velocity.

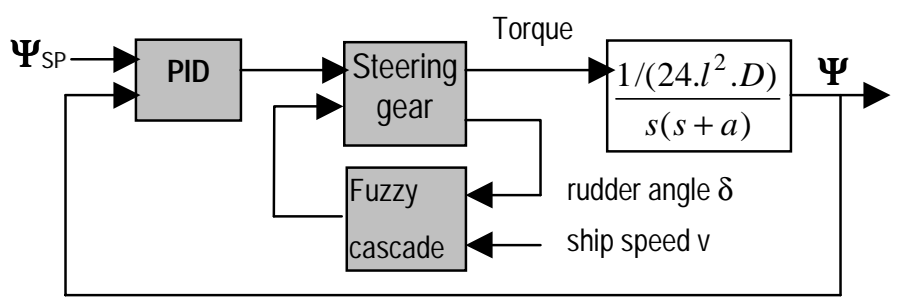

Figure 4: Simulation model for fuzzy cascade steering gear.

Above models shown in Figures 3 and 4 belong to the cargo container ship described in [1].

In order to compare dynamic results by simulation, a general block diagram implemented in simulink is shown in Figure 5.

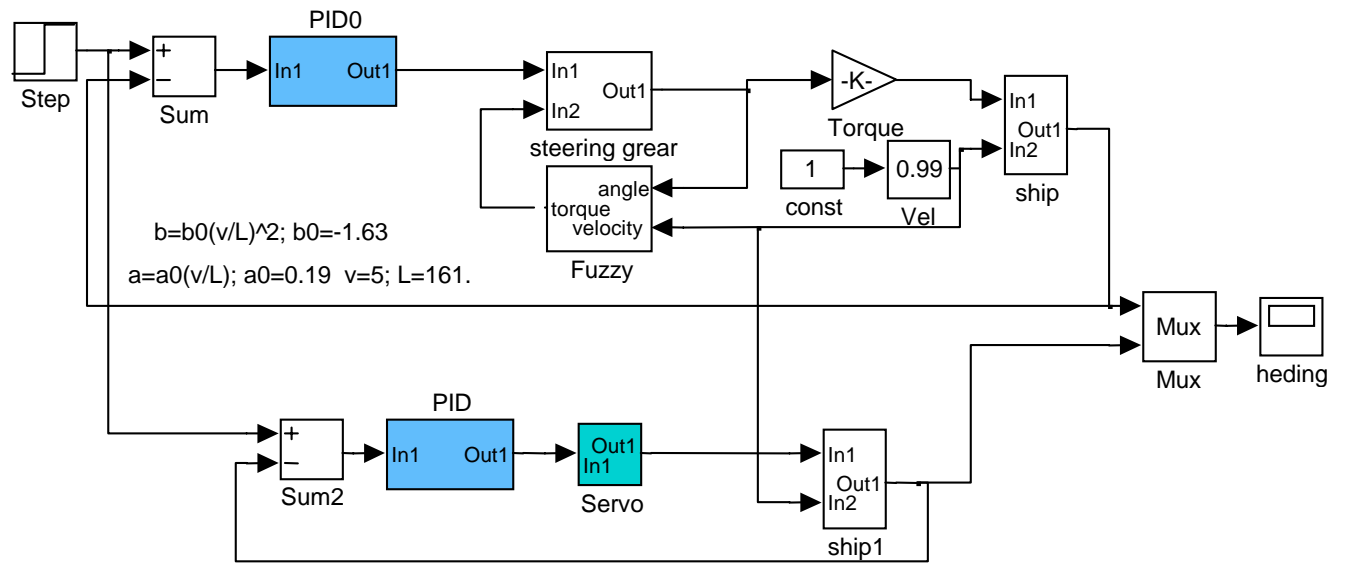

Figure 5: Simulink diagram for comparison purposes by simulation 
Cascade compensation is implemented by taking into account the rudder angle and ship speed to give the rudder torque. The rule base in matrix form is shown in Table 1.

\begin{tabular}{|c|c|c|c|c|c|c|c|c|c|}
\hline & $\begin{array}{l}-24 \\
\mathrm{NH}\end{array}$ & $\begin{array}{c}-18 \\
\text { NM }\end{array}$ & $\begin{array}{l}-12 \\
\text { NL }\end{array}$ & $\begin{array}{c}-6 \\
\text { NVL }\end{array}$ & $\begin{array}{l}\mathbf{0} \\
\mathbf{Z}\end{array}$ & $\begin{array}{c}6 \\
\text { VL }\end{array}$ & $\begin{array}{l}12 \\
\mathrm{~L}\end{array}$ & $\begin{array}{l}18 \\
\text { M }\end{array}$ & $\begin{array}{l}24 \\
\text { H }\end{array}$ \\
\hline $1 \mathrm{VL}$ & -2.3 & -1.7 & -1.16 & -0.6 & 0 & 0.6 & 1.16 & 1.7 & 2.3 \\
\hline $2 \mathrm{~L}$ & -21 & -16 & -10 & -5 & 0 & 5 & 10 & 16 & 21 \\
\hline $5 \mathrm{M}$ & -58 & -43.5 & -29 & -14.5 & 0 & 14.5 & 29 & 43.5 & 58 \\
\hline $7 \mathrm{H}$ & -114 & -85 & -57 & -28.5 & 0 & 28.5 & 57 & 85 & 114 \\
\hline
\end{tabular}

Table 1: Fuzzy rule base of cascade compensation.

\section{Simulation results}

Simulations on both ship models are performed to show the validity of the preliminary study for the proposed steering gear servo, operating at low or zero cruise ship's velocities. An automatic pilot with a PID control algorithm is applied. Controller parameters are adjusted so that a proper response is achieved at normal cruise speed. The layout of the simulation interface permits the adjustment of ship dynamic parameters such as ship speed in $\mathrm{m} / \mathrm{s}$, heading set point in degrees and controller parameters.

Figures 6, 7 and 8 shows the heading response at variable speed, varying from too low speed to a normal speed. Excitation variable is a zigzag applied to the heading set point. The results show how a simple servo implementation can improve manoeuvring capacity at low critic manoeuvring speeds. It has been shown that an acceptable heading motion response is achieved under speed restricted ship condition, particularly at near zero manoeuvring ahead /speeds. Nevertheless, astern speed is not applicable because the propeller interaction with rudder is only effective at ahead propulsion forces [5].

The main advantage in using this method is to keep the steering capacity at low ship velocities, which make the contribution particularly useful in manoeuvring tasks. The low cost implementation brings the possibility of using with some advantages an alternative steering equipment, which permits the scheduling under a simple strategy of both steering gear types, that are classical and new proposed methods according actual measured situation (manoeuvring conditions, trackkeeping, sea-keeping or dynamic positioning).

It has been shown that at very low speed classic angle feedback servo is not effective while torque feedback servo achieves proper performance. At higher speeds, the performance of proposed steering gear servo is closely similar to classic solutions.

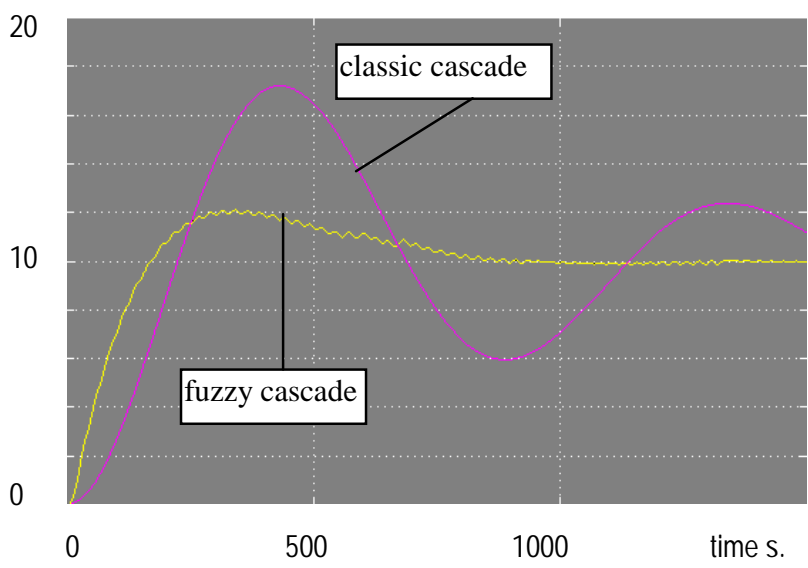

Figure 6: Heading response (degrees) at $2 \mathrm{kn}$. speed for conventional and fuzzy cascade.

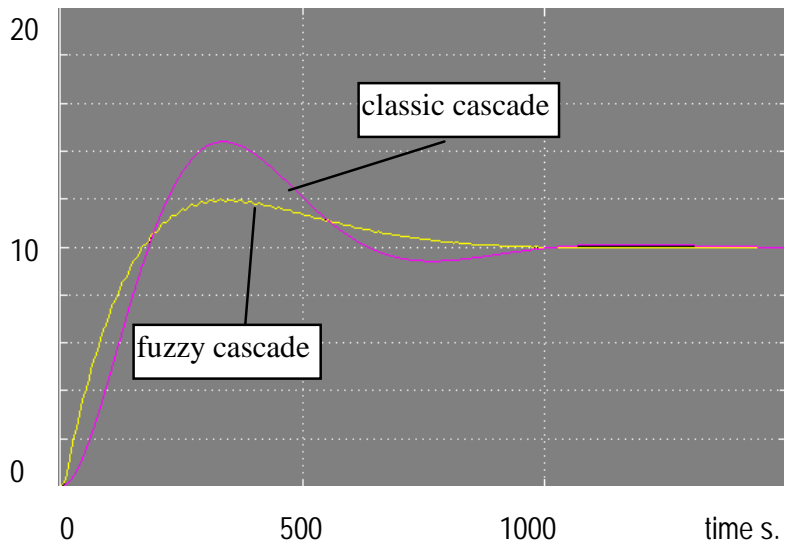

Figure 7: Heading response (degrees) at $3 \mathrm{kn}$. speed for conventional and fuzzy cascade.

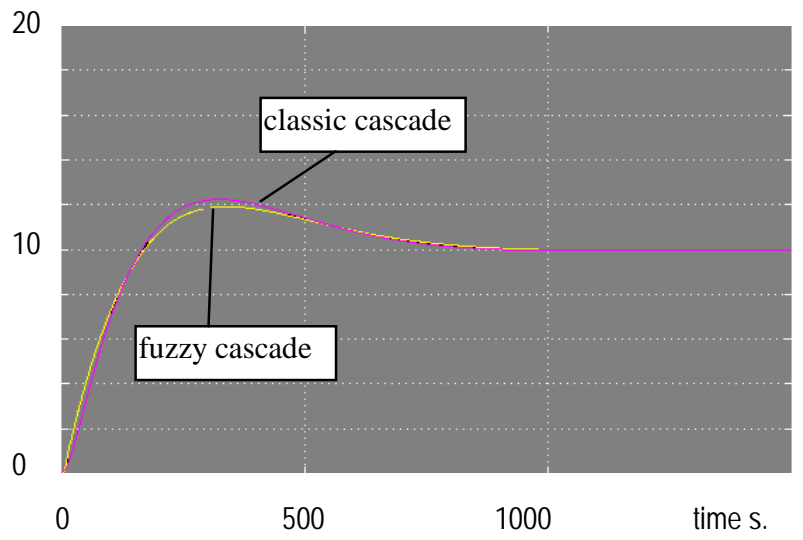

Figure 8: Heading response (degrees) at $6 \mathrm{kn}$. speed for conventional and fuzzy cascade.

\section{References}

[1] Astrom K.J., Wittenmark B. "Adaptive Control", Chap.9, pp.355-358, Addison-Wesley Publishing Company (1989). 
[2] F.H. "Todd Resistance and Propulsion", Principles of Naval Architecture, pp.373-397, $31^{\text {st }}$ edition. Society of Naval Architects and Marine Engineers. U.S.A.(1967).

[3] King R.E. "Computational Intellingence in Control Engineering”, Chap.8, pp.105-118, Marcel Decker, Inc. New York, U.S.A. (1999).

[4] Luyben W.L. "Process modeling, simulation, and control for chemical engineers", Chap.11, pp.383-391, McGraw-Hill, Inc U.S.A. (1989).

[5] Mandel P. "Ship Manoeuvring and Control", Principles of Naval Architecture, pp.489-510, Society of Naval Architects and Engineers. U.S.A. Society of Naval Architecture and Marine Engineers. U.S.A. (1967).

[6] Shinskey F.G.. "Process control systems. Applications, design and tuning", Chap.7, pp.267-309, McGraw-Hill, Inc U.S.A. (1996). 